\title{
A Call to Action: Setting the Research Agenda for Addressing Obesity and Weight-Related Topics in Children with Physical Disabilities
}

\author{
Amy C. McPherson, PhD, CPsychol,',2 Geoff D.C. Ball, PhD, RD, ${ }^{3}$ \\ Désirée B. Maltais, PhD, PT, 4,5 Judy A. Swift, MSc, PhD, ${ }^{6}$ John Cairney, PhD, ${ }^{7-9}$ \\ Tara Joy Knibbe, BA, MSc, and Kim Krog, RN, MScN, CRN $(C)^{1,10}$ \\ on behalf of DOCC-Net (Disability and Obesity in Canadian Children Network)
}

\section{Abstract}

Background: Pediatric obesity is a world-wide challenge. Children with physical disabilities are particularly at risk of obesity, which is worrisome because obesity can result in serious secondary conditions that decrease health status, reduce independence, and increase impact on healthcare systems. However, the determinants of obesity and the health promotion needs of children with physical disabilities are relatively unexplored compared with their typically developing peers.

Methods: This white paper describes a Canadian multistakeholder workshop on the topic of obesity and health in children with physical disabilities and provides recommendations for future research in this understudied area.

Results: Seventy-one knowledge gaps identified by attendees using a modified nominal group technique clustered into six themes: (1) early, sustained engagement of families; (2) rethinking determinants of obesity and health; (3) maximizing impact of research; (4) inclusive integrated interventions; (5) evidence-informed measurement and outcomes; and (6) reducing weight biases. Attendees worked together to develop research plans in more detail for three areas identified through consensus as high priority: "early, sustained engagement of families;" "rethinking determinants of obesity and health;" and "evidence informed measurement and outcomes."

Conclusions: Using the workshop described here as a call to action, Canadian researchers are now well positioned to work toward a greater understanding of weight-related topics in children with physical disabilities, with the aim of developing evidence-based and salient obesity prevention and treatment approaches.

\footnotetext{
'Bloorview Research Institute, Holland Bloorview Kids Rehabilitation Hospital, Toronto, Ontario, Canada.

${ }^{2}$ Dalla Lana School of Public Health and Rehabilitation Sciences Institute, University of Toronto, Toronto, Ontario, Canada.

${ }^{3}$ Department of Pediatrics, Faculty of Medicine \& Dentistry, University of Alberta, Edmonton, Alberta, Canada.

${ }^{4}$ Department of Rehabilitation, Laval University, Québec City, Québec, Canada.

${ }^{5}$ Center for Interdisciplinary Research in Rehabilitation and Social Integration, Québec City, Québec, Canada.

${ }^{6}$ School of Biosciences, The University of Nottingham, Nottingham, United Kingdom.

${ }^{7}$ Departments of Family Medicine, Psychiatry and Behavioral Neurosciences, and Kinesiology, Hamilton, Ontario, Canada.

${ }^{8}$ CanChild Center for Studies in Childhood Disability, Hamilton, Ontario, Canada.

${ }^{9}$ INCH Lab, McMaster University, Hamilton, Ontario, Canada.

${ }^{10}$ Lawrence S. Bloomberg Faculty of Nursing, University of Toronto. Toronto, Ontario, Canada.
}

(c) Amy C. McPherson et al. 2015; Published by Mary Ann Liebert, Inc. This Open Access article is distributed under the terms of the Creative Commons Attribution Noncommercial License (http://creativecommons.org/licenses/by-nc/4.0/) which permits any noncommercial use, distribution, and reproduction in any medium, provided the original author(s) and the source are credited. 


\section{Introduction}

$\mathbf{T}$ he World Health Organization has identified childhood obesity as a major 21 st century health problem. ${ }^{1}$ In Canada, the weights of children and young people (herein children) have risen over the previous 30 years such that $25-30 \%$ of Canadian children aged 2-17 years have overweight or obesity. ${ }^{2,3}$ Policy makers are unequivocal: We must act now to halt the rising tide of obesity and related diseases. ${ }^{3}$ One group at high risk for developing unhealthy weights is children with physical disabilities, representing $\sim 4-7 \%$ of young Canadians. ${ }^{4,5}$ Representing a diverse array of conditions, such as spina bifida, cerebral palsy, muscular dystrophy, acquired spinal injuries, and amputations, children with physical disabilities are disproportionately impacted by overweight and obesity compared with their typically developing peers. ${ }^{6,7}$ However, the short- and long-term health consequences of obesity in children who have a physical disability are relatively unknown, leading to them being described as an "underserved and marginalized population."7 The increasing number of children with physical disabilities, ${ }^{8}$ coupled with the high levels of overweight and obesity, ${ }^{3}$ underscores both the current and future impact on health and well-being, as well as the economic pressure these issues will exert on our healthcare system. ${ }^{9,10}$

\section{What DO we know?}

Compared with the extensive literature available for typically developing children, our understanding of obesity in children with physical disabilities is limited. Children with physical disabilities are diverse, with wide-ranging impairments and abilities. For example, children may be ambulatory, with or without a mobility device (e.g., anklefoot orthoses, walker), or may require a wheelchair full time. ${ }^{11}$ We also know that the environment - both physical and psychosocial - can limit the engagement of children with disabilities in health promoting activities, particularly physical activity (PA). ${ }^{12,13}$ For example, families of children with disabilities frequently have lower incomes than those with typically developing children, ${ }^{14}$ which can affect their children's participation in activities, ${ }^{15}$ the quality of their diet, ${ }^{16}$ as well as parents' availability to engage in additional services or programs. ${ }^{16}$ Together, these issues all increase the risk of both poor health and unhealthy weight gain in children with physical disabilities ${ }^{6,7}$ and can cause serious secondary conditions, such as pressure ulcers, pain, and severe muscle loss. ${ }^{17,18}$ This disables children further and amplifies their risk of obesity, ${ }^{18}$ reducing independence and increasing need for both informal caregiving and established healthcare services. ${ }^{19-21}$ Given that healthy nutrition, PA, and sedentary behaviors in adulthood are often rooted in childhood, positive health behaviors must start early. ${ }^{22-24}$ Conversely, painful physical therapy and exclusion from activities, such as physical education classes, as a child can discourage PA for life. ${ }^{25,26}$ Despite this, children with physical disabilities have largely been excluded from health promotion initiatives and associated research, ${ }^{27-29}$ limiting the evidence base upon which professionals can make decisions. Their exclusion from health-promoting activities has even wider implications, given that participation in society (or lack of) impacts physical and psychological health. ${ }^{30}$

\section{What do we NOT know?}

Since 2010, our research has identified a lack of evidence related to obesity prevention and management in children with physical disabilities. ${ }^{29,31-35}$ The significant gaps in the evidence base became clear in our team's scoping review of health promotion intervention studies (1987-2012) for children with physical disabilities. ${ }^{29}$ None of the 9913 articles described long-term obesity prevention interventions for this group. A limited number of publications $(n=34)$ describing intervention studies addressing nutrition or PA domains were found, but were mostly small scale or low methodological quality. Knowledge specific to Canadian children with physical disabilities was also sparse ( $n=3$ studies). In a recent systematic review of obesity prevention interventions in children, ${ }^{36}$ one quarter $(n=14)$ explicitly excluded children with any form of impairment, condition, or illness. Collectively, these data highlight the lack of scholarship in children with obesity and physical disabilities and demonstrate the extent to which they are marginalized.

Although two recent Canadian reports synthesized obesity-related research for typically developing children, ${ }^{3,37}$ further research is required to (1) understand how the findings can be applied to children with physical disabilities and (2) identify priority research areas for children with physical disabilities. In order to address these needs, we held a multistakeholder consensus- building workshop to identify key areas for obesity-related research related to children with physical disabilities.

\section{Aims}

The aims of the workshop were to: (1) identify clinically relevant research priorities, by leveraging the collective expertise of researchers, clinicians, and families; (2) identify potential obstacles to research initiatives and opportunities to overcome them; and (3) initiate a sustainable, collaborative national research network with links to international leaders. This article reports the findings from aims 1 and 2 with recommendations for future research directions. Equal consideration was given to both obesity prevention and management.

\section{Methods}

\section{Workshop description}

Attendees. The workshop was held over 2 days in October 2014 with 38 invited attendees: researchers $(n=12)$; trainees $(n=4)$; front-line clinicians $(n=12)$; parents $(n=3)$; former clients with disabilities $(n=1)$; community partners $(n=3)$; and decision makers $(n=3)$. Most invitees 
were Canadian and were identified (1) through the existing literature on disability and obesity (researchers and trainees), (2) by operations managers working in relevant clinical programs (clinicians), (3) from members of the Family Engagement Committee at the host pediatric rehabilitation hospital (parents/former clients), (4) staff members from local agencies, such as accessible fitness facilities (community partners), and (5) representatives from provincial health systems (decision makers). Integrating intersecting interests between the different stakeholders is consistent with recommendations for establishing research initiatives that are clinically relevant and acceptable to those for whom they are intended ${ }^{38,39}$ and represents an integrated knowledge translation approach. ${ }^{38}$ The participating family/ client stakeholders had previous experience of engaging in research discussions, and their involvement was supported through the Family Leadership Program at the host institution. Ethical approval was not required for the workshop.

\section{Agenda and activities}

We used multiple methods to guide the activities over the 2-day workshop, led by two experienced, certified facilitators external to the research team, allowing them to guide and empower attendees to identify priorities without imposing their own agenda. ${ }^{40}$ To ground the workshop in client and family-centered care, ${ }^{41}$ the first day started with two lived experience presentations by parents of children with a disability who had encountered challenges with obesity and weight management. The keynote speaker, Dr. James Rimmer, a noted authority on disability and obesity (e.g., in previous works ${ }^{10,27,28}$, then placed these experiences in context with his overview of the current state of science and future research needs for addressing health and weight management issues in children with physical disabilities. A series of 20- to 30-minute targeted, scientific presentations followed, providing the state of the evidence on the characteristics of effective weight management programs for typically developing children, the health promo- tion needs of children with physical disabilities identified to date, classifying overweight and obesity in children with physical disabilities and avoiding stigmatization, and methodological considerations when assessing lifestyle behaviors related to obesity and physical disability.

Presentations were followed by a group-based, facilitated visioning exercise to address the key question: What do we need to know more about over the next 2-5 years to help us better address obesity in children with physical disabilities? This exercise aimed to elicit diverse perspectives regarding current knowledge gaps. Using a modified nominal group technique, ${ }^{42}$ individuals first wrote knowledge gaps on cards and then discussed them within their small multistakeholder groups. Ideas were displayed for all workshop attendees to view and were subsequently grouped into six themes by the attendees through consensus discussions. Group interactions were facilitated to ensure that all attendees had an opportunity to participate and contribute their priorities.

On the second day, obstacles and opportunities for accomplishing the research within each of the six themes were identified, discussed, and recorded on paper in small groups. These data were later analyzed by the first author using a content analysis approach, conducting open coding on the written materials, followed by grouping codes into categories and then under higher-order headings. ${ }^{43}$ They were then reviewed, discussed, and agreed by the other authors.

Once the initial six themes had undergone the obstacles and opportunities analyses, facilitated consensus discussions enabled attendees to select three of the six original themes that they felt were the most appropriate and feasible for initiating the research efforts; individuals selfselected into one of the three groups. Each small group created a detailed written plan to guide initial research efforts. The workshop concluded with a brief presentation from each group of their plan and a large group discussion of next steps postworkshop.

\begin{tabular}{|c|c|c|c|c|c|}
\hline $\begin{array}{l}\text { Early, sustained } \\
\text { engagement of } \\
\text { families }\end{array}$ & $\begin{array}{c}\text { Rethinking } \\
\text { determinants of } \\
\text { obesity and health }\end{array}$ & $\begin{array}{l}\text { Maximizing impact } \\
\text { of research }\end{array}$ & $\begin{array}{l}\text { Inclusive integrated } \\
\text { interventions }\end{array}$ & $\begin{array}{l}\text { Evidence informed } \\
\text { measurement } \\
\text { and outcomes }\end{array}$ & $\begin{array}{c}\text { Reducing } \\
\text { weight biases }\end{array}$ \\
\hline $\begin{array}{l}\text { What are the } \\
\text { priorities of kids with } \\
\text { disabilities and } \\
\text { families? }\end{array}$ & $\begin{array}{l}\text { Who is at risk for } \\
\text { obesity (in children } \\
\text { with disability)? }\end{array}$ & $\begin{array}{l}\text { How are interventions } \\
\text { designed, implemented, } \\
\text { evaluated? }\end{array}$ & $\begin{array}{l}\text { How do we increase } \\
\text { integration to } \\
\text { prevent obesity? }\end{array}$ & $\begin{array}{l}\text { What are the } \\
\text { measurement issues } \\
\text { in this population? }\end{array}$ & $\begin{array}{l}\text { How do we } \\
\text { destigmatize } \\
\text { weight-related } \\
\text { communication? }\end{array}$ \\
\hline $\begin{array}{l}\text { How do we tailor } \\
\text { interventions to the } \\
\text { lifestyles of children } \\
\text { with disabilities? }\end{array}$ & $\begin{array}{l}\text { How do we use } \\
\text { critical thinking to } \\
\text { avoid repeating } \\
\text { previous mistakes? }\end{array}$ & $\begin{array}{l}\text { Should we prioritize } \\
\text { certain disabilities? }\end{array}$ & $\begin{array}{l}\text { What are the } \\
\text { preventative } \\
\text { strategies that are } \\
\text { inclusive? }\end{array}$ & $\begin{array}{l}\text { What outcomes are } \\
\text { we looking at or } \\
\text { should we be using? }\end{array}$ & $\begin{array}{l}\text { What are the weight } \\
\text { biases in healthcare? }\end{array}$ \\
\hline $\begin{array}{l}\text { How can we involve } \\
\text { children in program } \\
\text { development? }\end{array}$ & $\begin{array}{l}\text { How do we avoid } \\
\text { medication-related } \\
\text { weight gain? }\end{array}$ & $\begin{array}{l}\text { Is it possible to create } \\
\text { a universal treatment } \\
\text { guideline? }\end{array}$ & $\begin{array}{l}\text { How can social } \\
\text { inclusion empower } \\
\text { health? }\end{array}$ & $\begin{array}{l}\text { How do we define } \\
\text { and measure success } \\
\text { of interventions? }\end{array}$ & $\begin{array}{l}\text { How do we reduce } \\
\text { obesity-related } \\
\text { stigma? }\end{array}$ \\
\hline
\end{tabular}




\section{Table 2. Obstacles and Opportunities Identified Within the Six Initial Themes}

Obstacle

Opportunity

Original theme

I. Clinical practice and education

Lack of training for HCPs on including CWPD in programs/
interventions

Resistance in mainstream obesity world around positive weight-related communication

Parents and clinicians want "magic bullet" to lose lots of weight quickly.

Challenges in obtaining funding to support initiatives to develop evidence-informed measurement

Interpreting group data to individual and developmental stage of a child

\section{Research}

2.I Funding and methodological issues

Differing provincial mandates

Costs of setting up and conducting research

Low numbers of participants in individual centers

Need for long-term research and large numbers of participants

Financial and time barriers to study participation by families Lack of family motivation

Limited funding

Challenges in obtaining funding to support these initiatives

2.2 Client- and family-related engagement issues

Identify families ready to be involved in research

Lack of family familiarity of research processes, language

Negative past experiences with research

Determining what is "early" participation

Researcher giving up control

2.3 Targeted areas to research

Low-quality evidence available, especially in Canada

Lack of consensus on definition of obesity in CWPD

Lack of knowledge about what the determinants of obesity are

Unclear what impact parental capacity has on child's obesity

Assumption of parental barriers

Intuitive (incorrect) thinking around risk communication
Integrate into health professionals' curriculum

Leverage growing acceptance of the need for behavior change/mental health approaches, develop skills of clinicians

Be honest about what is possible

Increase awareness of the importance of valid outcome measures

Knowledge translation to HCPs

4

6

6

5

Leverage collaborators in different provinces

3

Conduct rigorous research to provide high-quality evidence that is generalizable

Develop and grow a network to link collaborators and centers together

Critically analyze existing research, leverage existing data sets, link centers together to increase numbers

Build support into grant funding to enable their participation Provide incentives: monetary, time, tax incentives

Collaborate with mental health colleagues (e.g., eating disorders)

Broaden funding horizons

5

Develop guidelines for approaching families at early stage

Develop evidence-based guideline and training (for researchers and clients/families)

Acknowledge people's experiences and build trust

Prevention focus, promote authentic engagement

Empowering clients/families to identify relevant questions /

outcomes and promote participation
3

2

I

4

6
Publish white paper on gaps and opportunities

Move away from standard height/weight assessment and move toward overall health assessment and overall risk screening for obesity

Start by focusing research on kids with physical disability specifically

Explore beliefs, model existing assessment systems (e.g., healthy babies home visiting program)

Develop good understanding of barriers from parents themselves

Continue to build evidence base that weight stigma is not effective
3

2

2

2

I

6

continued on page 63 
Table 2. Obstacles and Opportunities Identified Within the Six Initial Themes continued

\begin{tabular}{|c|c|c|}
\hline Fat activism/obesity deniers/Health At Any Size movement & Define weight stigma in relation to other movements & 6 \\
\hline $\begin{array}{l}\text { Difficulty in obtaining accurate measurements-lack of valid } \\
\text { and reproducible outcomes }\end{array}$ & Develop population-specific protocols & 5 \\
\hline Absence of reference data for interpretation & Collect and analyze in relation to health outcomes & 5 \\
\hline $\begin{array}{l}\text { Interpreting group data to individual and developmental stage } \\
\text { of a child }\end{array}$ & $\begin{array}{l}\text { Development of prognostic algorithms for clinical use using } \\
\text { multiple indicators and longitudinal evaluation of parameters } \\
\text { with respect to growth and maturation }\end{array}$ & 5 \\
\hline \multicolumn{3}{|l|}{ 3. Policy/positioning of issue } \\
\hline $\begin{array}{l}\text { Low value placed on overall health of people with physical } \\
\text { disabilities }\end{array}$ & Leverage discourses of social justice & 3 \\
\hline Stigma of participating in weight-/obesity-related research & $\begin{array}{l}\text { Put a "health" focus on conversation, normalize, open } \\
\text { conversation }\end{array}$ & 6 \\
\hline Lack of awareness of topic importance & $\begin{array}{l}\text { Increase disability representation-set indicators for visibility } \\
\text { and representation in the media; advocate for inclusive } \\
\text { policies }\end{array}$ & 4 \\
\hline Proximity of resources & $\begin{array}{l}\text { Capacity building in communities and promoting local } \\
\text { opportunities }\end{array}$ & 4 \\
\hline \multicolumn{3}{|l|}{ Original themes: } \\
\hline \multicolumn{3}{|l|}{ I. Early and sustained engagement of families. } \\
\hline \multicolumn{3}{|l|}{ 2. Rethinking determinants of obesity and health. } \\
\hline \multicolumn{3}{|l|}{ 3. Maximizing impact of research. } \\
\hline \multicolumn{3}{|l|}{ 4. Inclusive integrated interventions. } \\
\hline \multicolumn{3}{|l|}{ 5. Evidence-informed measurement and outcomes. } \\
\hline \multicolumn{3}{|l|}{ 6. Reducing obesity-related bias. } \\
\hline HCPs, health care providers; CWPD, children with physica & lisabilities. & \\
\hline
\end{tabular}

\section{Results}

\section{Priority themes}

In the initial visioning exercise, 71 knowledge gaps were identified, which clustered into six themes: (1) early and sustained engagement of families (21 knowledge gaps); (2) rethinking determinants of obesity and health (16 gaps); (3) maximizing impact of research (13 gaps); (4) inclusive integrated interventions (nine gaps); (5) evidence-informed measurement and outcomes (eight gaps); and (6) reducing weight biases (four gaps). Table 1 provides examples from the knowledge gaps identified (expressed as questions that attendees felt needed answering) that fell under each of the six themes. The full list of 71 knowledge gaps can be found at www.Hollandbloorview.ca/DOCCNet. Underpinning these themes was an emphasis on building upon existing knowledge from typically developing children and identifying transferable knowledge for children with obesity and physical disabilities.

\section{Obstacles and opportunities}

Within each of the six identified themes, potential challenges were identified and matched with an opportu- nity to overcome each obstacle. These obstacles and opportunities fell into three areas: (1) clinical practice and education; (2) research (subareas: funding and methodological issues; client and family engagement issues; and targeted areas to conduct research); and (3) policy-related issues and topic positioning. Table 2 presents these three key obstacle areas and the six original themes to which they belonged.

\section{Detailed development of prioritized research}

Having developed an understanding of the obstacles and opportunities associated with each of the six priority theme areas, the attendees were then in a position to select three of the areas that they felt were the most appropriate and feasible for moving the research agenda forward initially, which were then explored in more detail in order to make recommendations.

(1) Early and sustained engagement of families. Workshop attendees believed it was critical to identify family priorities and engage families in order to ensure timely, meaningful research. ${ }^{44}$ Assessing family acceptability and feasibility of interventions within a specific rehabilitation 
Table 3. Recommendations From Working Groups on (I) Early, Sustained Family Engagement in Research and (2) Evidence-Informed Measurement and Outcomes

Recommendation Strategy

Early, sustained engagement of families in obesity-related research for children with physical disabilities

\begin{tabular}{|c|c|}
\hline Identify best practices for engaging families in obesity-related research & - Conduct comprehensive scoping review of best practices \\
\hline Identify groups that are doing this well already & - Conduct an international environmental scan of existing resources \\
\hline Explore how families want to be engaged in research & $\begin{array}{l}\text { - Conduct focus groups with parents, children, community partners } \\
\text { (e.g., schools) } \\
\text { - Conduct scoping review (as above) }\end{array}$ \\
\hline Develop guidelines for engaging families in obesity research & $\begin{array}{l}\text { - Use findings from above strategies to develop initial guidelines for } \\
\text { engaging families }\end{array}$ \\
\hline Explore perspectives of all stakeholders & $\begin{array}{l}\text { - Engage child, family, community partners, researchers, clinicians to } \\
\text { identify research priorities }\end{array}$ \\
\hline \multicolumn{2}{|c|}{ Evidence-informed measurement and outcomes for children with physical disabilities } \\
\hline $\begin{array}{l}\text { Collaborate with researchers developing alternative assessment } \\
\text { approaches to BMI }\end{array}$ & $\begin{array}{l}\text { - Edmonton Obesity Staging System-Pediatric }{ }^{56} \\
\text { - Healthy Body Score Card }\end{array}$ \\
\hline $\begin{array}{l}\text { Partner with mainstream obesity groups to explore adaptation of } \\
\text { assessments embedded in current prevention and management } \\
\text { guidelines }\end{array}$ & - Canadian Obesity Network: 5As of Pediatric Weight Management \\
\hline $\begin{array}{l}\text { Create expert committee to identify clinically meaningful cutoffs using } \\
\text { existing anthropometric tools }\end{array}$ & $\begin{array}{l}\text { - Weight, height, waist circumference, skinfold thickness } \\
\text { - Test cutoffs developed through consensus using cardiometabolic } \\
\text { indicators in different diagnostic groups }\end{array}$ \\
\hline $\begin{array}{l}\text { Research needed on feasibility, acceptability, and reliability of } \\
\text { anthropometric tools in different diagnostic groups }\end{array}$ & $\begin{array}{l}\text { - Engage families, clinicians, and researchers to assess feasibility, } \\
\text { acceptability, and reliability }\end{array}$ \\
\hline
\end{tabular}

context was deemed particularly important, given the potential differences in causes and consequences of obesity in children with different physical disabilities. Families of children with physical disabilities have many additional commitments that may restrict the time and resources available for participating in activities such as research projects. This needs to be taken into consideration when planning family engagement activities in both research and treatment contexts. The first steps needed to achieve this vision and their associated methodological approaches are outlined at the top of Table 3.

(2) Rethinking the determinants of obesity and health. A recurring issue throughout the workshop was the lack of an existing conceptual framework to guide research. Therefore, one group of attendees developed an iterative biopsychosocial conceptual model of obesity and health relevant to children with physical disabilities, which could both guide and be informed by research (see Fig. 1). This model extends previous work by Liou and colleagues, who proposed a biomedical conceptual model to explain the mechanisms underlying obesity and disability. ${ }^{18}$ In the 10 years since Liou and colleagues' model, we have become increasingly aware of the social and environmental factors that influence obesity as a complex disease. This led to Fox and colleagues' proposal of a systems-level model to re- duce obesity in people with disabilities, taking a public health policy stance, including national/global determinants and community-based determinants. ${ }^{12}$

Our proposed conceptual model brings a somewhat different lens, whereby health is the primary outcome in the model, not weight. Whereas weight can impact health, having health as an outcome allows for a more clientcentered approach, where the targeted health outcomes for each person can be determined by the individual in conjunction with their family and their healthcare team. This approach aligns well with the International Classification of Functioning, Health and Disabilities (ICF), which does not confer "ill health" purely because of an impairment of body structure $^{30}$ (in the case of obesity, we could consider this to be excess adipose tissue; see a previous work ${ }^{45}$ ). The proposed model is high level, but incorporates contributors to health and obesity that appear to be distinct in children with physical disabilities. Environmental, social, and individual factors affecting diet, PA, sedentary behaviors, and energy metabolism may have differential impacts in children with physical disabilities versus typically developing children (e.g., the presence of Chiari II brain malformations in children with spina bifida can affect swallowing, gagging, food preferences, and breathing). ${ }^{19,46}$ These in turn can contribute to restricted diet, sedentary lifestyles, and reduced physical fitness. ${ }^{47-50}$ Inaccessible fitness facilities, social isolation, and highly protective parenting may also 


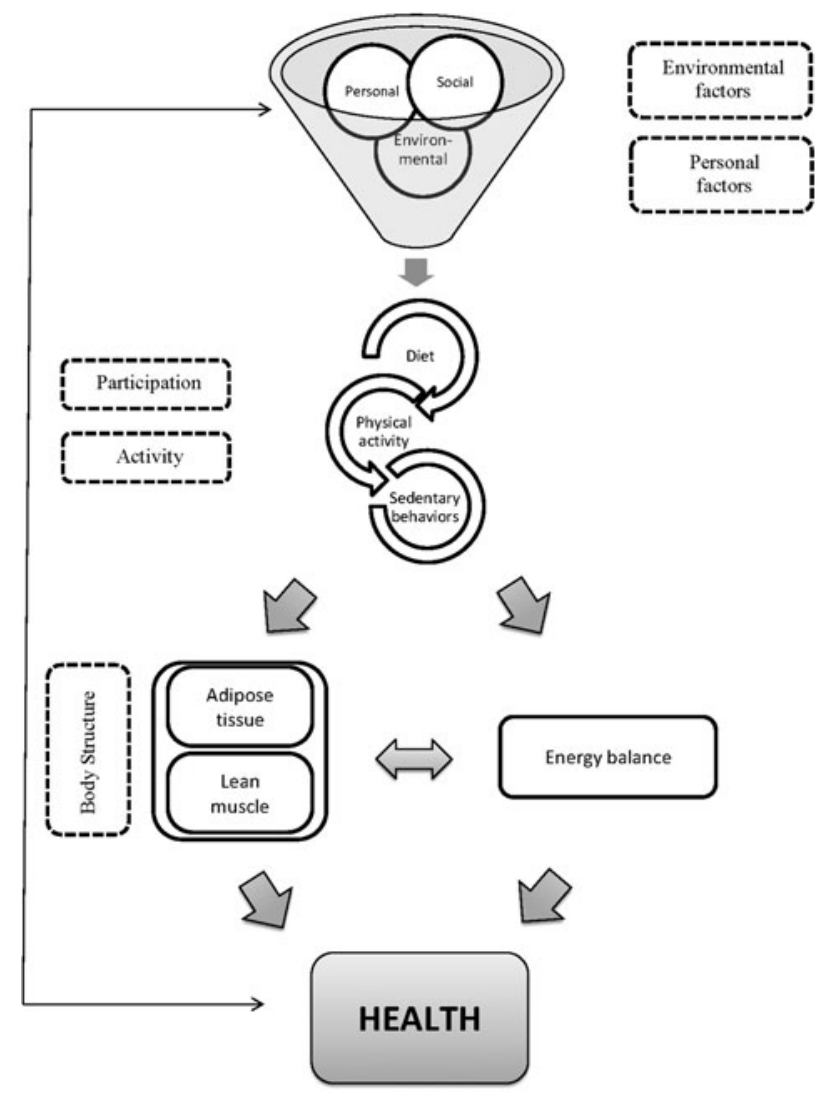

Figure 1. Conceptual model of physical disability, obesity, and health. NB. Shapes with dotted lines indicate concepts from the International Classification of Functioning, Disability and Health. ${ }^{30}$

exert influence upon weight-related behaviors in children with physical disabilities more than their typically developing peers. ${ }^{13,51,52}$ These factors, which may overlap, are also likely to influence children's perceptions of health, ${ }^{53}$ so relationships are conceptualized as multidirectional. If we overlay the ICF concepts on our model, the activities and participation of children with physical disabilities are also likely to be affected. We recognize that factors other than direct behaviors may also influence weight. For example, the role of sleep as a potential mediator is an emerging area of interest and may warrant inclusion once more explanatory evidence is available. Exploring energy balance and its effect upon adipose and lean tissue will also be a critical area of future research to inform the model, given that many children with physical disabilities differ from their typically developing peers regarding body composition. ${ }^{54,55}$ All of this means that we have to "rethink" health promotion approaches used with typically developing children when working with children with physical disabilities to ensure that we meet their biopsychosocial needs.

(3) Evidence-informed measurement and outcomes. A key challenge facing clinicians and researchers is the lack of standardized, accurate, and acceptable (both to the patients and in a clinic environment) measurement tools to assess children with physical disabilities. This impacts both clinical monitoring of children and classification of body weight status, ${ }^{32}$ as well as the evaluation of intervention impact. Two primary strategies to address this problem were proposed: first, the creation of an expert committee, to develop practice guidelines using existing anthropometric assessments (e.g., weight, height, and waist circumference) for different populations, which could be empirically tested. Second, we can leverage existing partnerships, both with mainstream organizations (e.g., Canadian Obesity Network) and research groups investigating assessments that can be used in conjunction with BMI (e.g., Edmonton Obesity Staging System-Pediatrics ${ }^{56}$ and The Healthy Body Scorecard ${ }^{5,58}$ ) to provide a broader understanding of an individual's health status. See the bottom of Table 3 for recommendations and strategies relating to outcome measure development.

\section{Discussion}

Childhood obesity is a global concern, ${ }^{1}$ yet children with physical disabilities have been largely excluded from research addressing health promotion issues, such as obesity, PA, and diet. ${ }^{7,29}$ The workshop provided a knowledge exchange opportunity for a diverse group of experts to discuss existing gaps and challenges from multiple perspectives (including those of families), prioritize areas for initial research efforts, and build collaborative relationships. Recommendations emerging from the workshop's multistakeholder consensus activities included:

1. Children's and families' needs must be integrated into prevention and treatment programs, taking into account the additional caring commitments and environmental challenges often experienced by families of children with physical disabilities. Guidelines need to be developed regarding how best to engage children/families meaningfully in designing both clinical interventions and health promotion research initiatives.

2. Research in obesity and health in children with physical disabilities should be guided by a conceptual model, determining both common and unique determinants of health and obesity compared with their typically developing peers. A conceptual model enables existing knowledge about obesity prevention and management from other populations to be integrated into approaches for children with physical disabilities where appropriate, as well as the identification of areas where disabilityspecific knowledge is still needed. It is critical that any such model incorporates social and environmental factors that can affect both weight and health, rather than locating responsibility within the individual by default. ${ }^{45}$ The alignment of our model with the ICF ensures that our approach remains truly biopsychosocial.

3. Valid, reliable, clinically appropriate, and acceptable outcome measures are urgently needed in order to monitor children's weight and health, and identify overweight and obesity, where conventional outcomes (e.g., BMI) alone have been shown as suboptimal. 
These recommendations also have relevance to typically developing children. For instance, parents play a valuable role in providing a supportive environment conducive to developing healthy eating and activity habits for all children, ${ }^{59,60}$ and engaging parents of typically developing children is a key element of many children's weight management programs, given their influence on their child's participation. ${ }^{61-64}$ However, the priorities of children with physical disabilities and their families may differ, given the additional health and psychosocial concerns that a physical disability can bring, ${ }^{65,66}$ which requires further explication. This is the focus of one part of a large team grant on severe obesity and bariatric care secured by our team, but will also require ongoing exploration.

Traditionally, there has been a substantial disparity between those conducting research and those who are the focus of the research, with researchers assuming a position of "expert." 67 Where families are involved in research studies, involvement can often be tokenistic. ${ }^{68} \mathrm{We}$ are confident that the priorities of families are fully integrated into our proposed strategic directions for a number of reasons. First, the host facility for the workshop, Holland Bloorview Kids Rehabilitation Hospital, has a rich culture of child- and family-centered care, using a number of different vehicles to deliver their commitment to stakeholder engagement, including two family advisory committees. The parents and former client who attended the workshop were all part of the hospital's Family Leadership Program, which supports parents to make meaningful contributions to initiatives across the hospital terms, including research. Second, using certified facilitators external to the research team enabled all workshop participants to contribute fully to the discussions and priority-setting exercises. Last, the authentic involvement of families in the workshop is highlighted by the first of our three recommendations for future research directions.

Ongoing relationships between workshop attendees are being facilitated by the creation of the Disability and Obesity in Canadian Children Network (DOCC-Net), which aims to build multistakeholder collaborations around obesity- and weight-related issues with children with disabilities, and ensure that the resulting research is scientifically robust, clinically meaningful, and grounded in child and family priorities. The website for DOCC-Net (www .hollandbloorview.ca/doccnet) is designed to be used in both "push" (e.g., providing key references, highlighting consensus documents) and "pull" (e.g., harnessing existing knowledge) knowledge translation activities. ${ }^{69}$ It will also communicate research findings to different audiences (e.g., families, researchers, clinicians, and decision makers) within and beyond Canada. To raise the visibility of disability and obesity research, DOCC-Net will leverage members' existing partnerships in the mainstream obesity field (e.g., the Canadian Obesity Network [CON]), child health (e.g., Canadian Association of Pediatric Health Centers Children's Treatment Centres [CAPHC]), and pediatric rehabilitation (e.g., Canadian Network for Child and
Youth Rehabilitation [CN-CYR]). The benefits of these partnerships include leveraging existing resources and/or infrastructure, as well as increasing study sample sizes, thereby resulting in greater impact of research.

\section{Identified challenges}

The workshop engaged many different stakeholders, but despite our concerted efforts, no children or youth participated in person. Two young adults provided their personal views by e-mail and gave permission for them to be integrated anonymously into one of the scientific talks. In addition to logistical reasons (e.g., availability during weekdays), the reluctance of children to accept our invitations to the workshop may reflect the considerable stigma still attached to obesity. ${ }^{70,71}$ We considered our workshop to be a safe and accepting environment for young people living with obesity to contribute their important views - for example, it involved a relatively small number of highly engaged participants experienced in working with vulnerable populations, support was available before, during and after the workshop, and other (unrelated) family members were participating. However, work is clearly still needed to facilitate meaningful youth engagement in research priority-setting. As ongoing, trusting relationships are advocated for successful obesity discussions and treatment with children and families, ${ }^{72,73}$ convening ongoing youth advisory committees on health promotion may be a more fruitful approach than inviting young people to join one-off events. It will be critical to partner with youth as we move forward with the identified research directions to ensure that their voice is represented. Although there were no youth participants, some workshop participants did have visible disabilities. We were also able to include a range of other key stakeholders, including parents of children experiencing weight-related issues.

Workshop attendees came from across 4 of the $10 \mathrm{Ca}$ nadian provinces. No differences were identified in the experiences of those attending from different provinces, although policy contexts could potentially vary. DOCCNet will be widely promoted across all Canadian provinces and disseminated through pan-Canadian organizations (e.g., $\mathrm{CON}, \mathrm{CAPHC}$, and $\mathrm{CN}-\mathrm{CYR}$ ). International partners will also be encouraged to contribute their expertise to DOCC-Net and disseminate relevant information across their networks.

\section{Conclusions}

Research into weight-related topics in children with physical disabilities is sparse, despite constituting a highrisk population. Using the workshop described here as a call to action, we are now well positioned to work toward evidence-based services for children with physical disabilities that are "the same range, quality and standard of free or affordable health care and programmes as provided to other persons." 74 There is a long way to go before 
the prevention and management of pediatric obesity and optimal health promotion is fully understood; however, we need to include children with physical disabilities and their families in that journey.

\section{Acknowledgments}

This work was funded by a planning grant from the Canadian Institutes of Health Research (KTM-133834), with additional funding from Holland Bloorview Kids Rehabilitation Hospital and Bloorview Research Institute. The authors thank all of the workshop participants for their contributions, including the family members. The authors also thank Joan Walker for her assistance in workshop planning. We are grateful to the self-nominated workshop attendees who reviewed the manuscript for accuracy, conceptual completeness, and use of appropriate language.

\section{Author Disclosure Statement}

No competing financial interests exist.

\section{References}

1. World Health Organization. Childhood overweight and obesity. 2009. Available at www.who.int/dietphysicalactivity/childhood/ en/index.html Last accessed December 12, 2015.

2. Shields M. Overweight and obesity among children and youth. Statistics Canada: Ottawa, Ontario, Canada, 2006.

3. Healthy Kids Panel. No time to wait: The healthy kids strategy. Ministry of Health and Long Term Care, Ontario. 2013. Available at www.health.gov.on.ca/en/common/ministry/publications/ reports/healthy_kids/healthy_kids.pdf Last accessed Month day, year.

4. McDougall J, King G, de Wit DJ, et al. Chronic physical health conditions and disability among Canadian school-aged children: A national profile. Disabil Rehabil 2004;26:35-45.

5. Canadian Institutes of Child Health. The Health of Canada's Children: A CICH Profile. Children and youth with disabilities. Canadian Institutes of Child Health: Ottawa, Ontario, Canada, 2010.

6. Neter JE, Schokker DF, de Jong E, et al. The prevalence of overweight and obesity and its determinants in children with and without disabilities. J Pediatr 2011;158:735-739.

7. Rimmer J, Rowland J, Yamaki K. Obesity and secondary conditions in adolescents with disabilities: Addressing the needs of an underserved population. J Adolesc Health 2007;41:224-229.

8. Statistics Canada. Participation and activity limitation Survey 2006: Families of children with disabilities in Canada. Statistics Canada: Ottawa, Ontario, Canada, 2008.

9. Short KR, Frimberger D. A review of the potential for cardiometabolic dysfunction in youth with spina bifida and the role for physical activity and structured exercise. Int $J$ Pediatr 2012; 2012:541363.

10. Rimmer JH. Promoting inclusive community-based obesity prevention programs for children and adolescents with disabilities: The why and how. Child Obes 2011;7:177-184.
11. Copp A, Adzick N, Chitty LS, et al. Spina bifida. Nat Rev Dis Primer 2015;Article number:15007. doi: 10.1038/nrdp.2015.7.

12. Fox MH, Witten MH, Lullo C. Reducing obesity among people with disabilities. J Disabil Pol Stud 2014;25:175-185.

13. Buffart L, Westendorp T, van den Berg-Emons RJ, et al. Perceived barriers to and facilitators of physical activity in young adults with childhood-onset physical disabilities. J Rehabil Med 2009;41:881885.

14. Parish S, Cloud J. Financial well-being of young children with disabilities and their families. Soc Work 2006;51:223-232.

15. Shikako-Thomas K, Majnemer A, Law M, et al. Determinants of participation in leisure activities in children and youth with cerebral palsy: Systematic review. Phys Occup Ther Pediatr 2018; 28:155-169.

16. Park J, Turnbull AP, Turnbull AR. Impacts of poverty on quality of life in families of children with disabilities. Except Child 2002;68:151-170.

17. Simeonsson R, McMillen J, Huntington GS. Secondary conditions in children with disabilities: Spina bifida as an example. Ment Retard Dev Disabil Dis Rev 2002;8:198-205.

18. Liou T, Pi-Sunyer F, Laferrère B. Physical disability and obesity. Nutr Rev 2005;63:321-331.

19. Dosa N, Foley J, Eckrich M, et al. Obesity across the lifespan among persons with spina bifida. Disabil Rehabil 2009;31:914 920.

20. McDonald C, Widman L, Walsh SA, et al. Energy cost of wheelchair locomotion in thoracic and lumbar myelomeningocele and spinal cord injury - impact of diagnosis, gender, and body composition. Dev Med Child Neurol 2001;43:8.

21. Spina Bifida Association. Fact sheets-obesity. 2009. Available at wwwspinabifidaassociationorg/site/cliKWL7PLLrF/b2700287/ $\mathrm{kC25F} /$ Obesityhtm Last accessed Month day, year.

22. Government of Canada. The well-being of Canada's young children. Human Resources and Social Development Canada: Ottawa, Ontario, Canada, 2007, pp. 1-62.

23. Stock S, Miranda C, Evans S, et al. Healthy Buddies: A novel, peer-led health promotion program for the prevention of obesity and eating disorders in children in elementary school. Pediatrics 2007;120:e1059-e1068.

24. Piko B, Bak J. Children's perceptions of health and illness: Images and lay concepts in preadolescence. Health Educ Res 2006;21: 643-653.

25. Gaskin C, Andersen M, Morris T. Physical activity in the life of a woman with cerebral palsy: Physiotherapy, social exclusion, competence, and intimacy. Disabil Soc 2012;27:205-218.

26. Qi J, Ha A. Inclusion in physical education: A review of literature. Int J Disabil Dev Ed 2012;59:257-281.

27. Rimmer J, Rowland J. Physical activity for youth with disabilities: A critical need in an underserved population. Dev Neurorehabil 2008;11:141-148.

28. Rimmer JH, Yamaki K, Davis BM, et al. Obesity and overweight prevalence among adolescents with disabilities. Prev Chronic Dis 2011;8:A41.

29. McPherson A, Keith R, Swift JA. Obesity prevention for children with physical disabilities: A scoping review of physical activity and nutrition interventions. Disabil Rehabil 2013;36:1573-1587.

30. World Health Organization. International Classification of Functioning, Disability and Health. World Health Organization: Geneva, Switzerland, 2001

31. McPherson A, Keith R, Swift JA, et al. (eds). Interventions for obesity in young people with disabilities: Need for action. In: The 4th Conference on Recent Advances in the Prevention and Management 
of Childhood and Adolescent Obesity, October 24-26, 2012, Halifax, Nova Scotia, Canada.

32. McPherson A, Leo J, Chruch P, et al. An environmental scan of weight assessment and management practices in paediatric spina bifida clinics across Canada. J Pediatr Rehabil Med 2014;7:207217.

33. McPherson A, Swift J, Yung E, et al. Overweight and obesity among children and youth with spina bifida: A retrospective medical records review. In: Second World Congress on Spina Bifida Research and Care, March 11-14, 2012, Las Vegas, NV.

34. McPherson A, Swift J, Yung E, et al. A retrospective medical record review of overweight and obesity in children with spina bifida. Disabil Rehabil 2013;35:2123-2131.

35. Yung E, Swift J, Church P, et al. Overweight and obesity among children and youth with Spina bifida: A retrospective medical records review. In: 5th Annual Anne \& David Ward Summer Student Research Day, 2011: Toronto, Ontario, Canada.

36. Waters E, de Silva-Sanigorski A, Hall BJ, et al. Interventions for preventing obesity in children. Cochrane Database Syst Rev 2011;(12):CD001871.

37. Ontario Agency for Health Protection and Promotion. Addressing obesity in children and youth: Evidence to guide action for Ontario. Queen's Printer for Ontario: Toronto, Ontario, Canada, 2013.

38. Canadian Institutes of Health Research. Guide to Knowledge Translation planning at CIHR: Integrated and end-of-grant approaches. Canadian Institutes of Health Research: Ottawa, Ontario, Canada, 2012.

39. Jinks A, Cotton A, Rylance R. Obesity interventions for people with a learning disability: An integrative literature review. $J A d v$ Nurs 2010;67:460-471.

40. Azer SA. Challenges facing PBL tutors: 12 tips for successful group facilitation. Med Teach 2005;27:676-681.

41. King G, Chiarello L. Family-centered care for children with cerebral palsy: Conceptual and practical considerations to advance care and practice. J Child Neurol 2014;29:1046-1054.

42. Murphy M, Black N, Lamping DL, et al. Consensus development methods, and their use in clinical guideline development: A review. J Health Serv Res Policy 1998;2:i-iv, 1-88.

43. Elo $\mathrm{S}$, Kyngäs $\mathrm{H}$. The qualitative content analysis proces. $J A d v$ Nurs 2007;62:107-115.

44. Lindenmeyer A, Hearnshaw H, Sturt J, et al. Assessment of the benefits of user involvement in health research from the Warwick Diabetes Care Research User Group: A qualitative case study. Health Expect 2007;10:268-277.

45. Forhan M. An analysis of disability models and the application of the ICF to obesity. Disabil Rehabil 2009;31:1382-1388.

46. Liptak G, Samra A. Optimizing health care for children with spina bifida. Dev Disabil Res Rev 2010;16:66-75.

47. Buffart L, van den Berg-Emons H, van Wijlen-Hempel MS, et al. Health-related physical fitness of adolescents and young adults with myelomeningocele. Eur J Appl Physiol 2008;108:181-188.

48. Buffart L, Roebroeck M, Rol M, et al.; Transition Research Group South-West Netherlands. Triad of physical activity, aerobic fitness and obesity in adolescents and young adults with myelomeningocele. J Rehabil Med 2008;40:70-75.

49. Dicianno BE, Bellin MH, Zabel AT. Spina bifida and mobility in the transition years. Am J Phys Med Rehabil. 2009;88(12).

50. Liusuwan R, Widman L, Abresch RT, et al. Body composition and resting energy expenditure in patients aged 11 to 21 years with spinal cord dysfunction compared to controls: Comparisons and relationships among the groups. J Spinal Cord Med 2007;30(Suppl 1): S105-S111.
51. Dunn N, Shields N, Taylor NF, et al. Comparing the self concept of children with cerebral palsy to the perceptions of their parents. Disabil Rehabil 2009;31:387-393

52. Shimmell L, Gorter J, Jackson D, et al. "It's the participation that motivates him": Physical activity experiences of youth with cerebral palsy and their parents. Phys Occup Ther Pediatr 2013; 33:405-420.

53. Verhoef M, Post M, Barf HA, et al. Perceived health in young adults with spina bifida. Dev Med Child Neurol 2007;49: 192-197.

54. Wittenbrook W. Best practices in nutrition for children with myelomeningocele. Infant Child Adolesc Nutr 2010;2:237-245.

55. Grogan C, Ekvall S. Body composition of children with myelomeningocele, determined by ${ }^{40} \mathrm{k}$, urinary creatinine and anthropometric measures. J Am Coll Nutr 1999;18:316-323.

56. Hadjiyannakis S, Buchholz A, Chaoine JP, et al. The Edmonton Obesity Staging System for Pediatrics (EOSS-P): A proposed clinical staging system for pediatric obesity. Can $J$ Diabetes 2013;37(Suppl 2):S240. doi: 10.1016/j.jcjd.2013.03.145.

57. Patton I, McPherson A. Understanding health screening practices among Canadian practitioners working with children with disabilities. Disabil Health J. Under review.

58. Patton I, McPherson A. Beyond Weight: Development of a tool to support comprehensive paediatric screening practices. Paediatr Child Health. Under review.

59. Avis LS, Cave LA, Donaldson S, et al. Working with parents to prevent childhood obesity: Protocol for a primary care-based eHealth study. JMIR Res Protoc 2015;4:e35.

60. Trost SG, Sallis JF, Pate RR, et al. Evaluating a model of parental influence on youth physical activity. Am J Prev Med 2003; 25:277-282.

61. Ball GD, Ambler KA, Keaschuk RA, et al. Parents as Agents of Change (PAC) in pediatric weight management: The protocol for the PAC randomized clinical trial. BMC Pediatr 2012;12: 114.

62. Ball G, Garcia A, Chanoine JP, et al. Should I stay or should I go? Understanding families' decisions regarding initiating, continuing, and terminating health services for managing pediatric obesity: The protocol for a multi-center, qualitative study. BMC Health Serv Res 2012;12:486.

63. Stewart L, Chapple J, Hughes AR, et al. Parents' journey through treatment for their child's obesity: A qualitative study. Arch Dis Child 2008;93:35-39.

64. Schwartz R, Hamre R. Office-based motivational interviewing to prevent childhood obesity: A feasibility study. Arch Pediatr Adolesc Med 2007;161:495-501.

65. Stewart M, Barnfather A, Magill-Evans J, et al. Brief report: An online support intervention: Perceptions of adolescents with physical disabilities. J Adolesc 2011;34:795-800.

66. Antle B, Mills W, Steele C, et al. An exploratory study of parents' approaches to health promotion in families of adolescents with physical disabilities. Child Care Health Dev 2007;34:185-193.

67. Kitchin R. The researched opinions on research: Disabled people and disability research. Disabil Soc 2000;15:25-47.

68. Carman K, Dardess P, Maurer M, et al. Patient and family engagement: A framework for understanding the elements and developing interventions and policies. Health Aff (Millwood) 2013;32:223-231.

69. Gagnon M. Dissemination and exchange of knowledge In: Graham I, Straus S, Tetroe J (eds), Knowledge Translation in Health Care: Moving from Evidence to Practice. Canadian Institutes of Health Research: Ottawa, Ontario, Canada, 2011. 
70. Puhl R. Weight stigmatization toward youth: A significant problem in need of societal solutions. Child Obes 2011;7:359-363.

71. Puhl R, Latner J. Stigma, obesity, and the health of the nation's children. Psychol Bull 2007;133:557-580.

72. Farnesi BC, Ball GD, Newton AS, et al. Family-health professional relations in pediatric weight management: An integrative review. Pediatr Obes 2012;7:175-186.

73. McPherson A, Swift J, Peters M, et al. Communicating about obesity and weight-related topics with children with a physical disability and their families: Spina bifida as an example. Disabil Rehabil Under review.

74. United Nations. Convention on the Rights of Persons with Disabilities. 2008. Available at www.un.org/disabilities/documents/ convention/convoptprot-e.pdf Last accessed Month day, year.
Address correspondence to: Amy C. McPherson, PhD, CPsychol Scientist, Bloorview Research Institute Holland Bloorview Kids Rehabilitation Hospital Assistant Professor, Dalla Lana School of Public Health and Rehabilitation Sciences Institute

University of Toronto 150 Kilgour Road Toronto, Ontario Canada M4G $1 R 8$

E-mail: amcpherson@hollandbloorview.ca 